\title{
THE MODIFIED NORWOOD PALLIATION ON A BEATING HEART
}

Hidefumi Kishimoto, MD, Youichi Kawahira, MD, Hiroaki Kawata, MD, Takuya Miura, MD, Shigemitu Iwai, MD, and

Toru Mori, MD, Osaka, Japan

Hypoplastic left heart syndrome is a common congenital heart defect that carries a mortality rate of $95 \%$ in the first month after birth if left untreated. ${ }^{1}$ The Norwood operation, performed as a first palliative procedure for this syndrome, has proved challenging. ${ }^{2-4}$ Since 1992 we have performed the modified Norwood operation on the beating heart for hypoplastic left heart syndrome. ${ }^{5}$

Operative technique. Median sternotomy was performed. Cardiopulmonary bypass was established with bicaval cannulation. An arterial cannula (2.1 mm in diameter, JMS Co, Ltd, Hiroshima, Japan) was inserted into the right brachiocephalic artery, with another cannula into the descending aorta. After extensive dissection of the ascending aorta and the branch arteries of the aortic arch, an aortic crossclamp was placed at the proximal aortic arch to maintain coronary and cerebral perfusion. The left carotid artery and the left subclavian artery were also clamped. After the ductal tissue was removed, the incision was extended along the lesser curvature of the aortic arch without involving the origin of the brachiocephalic artery. The pulmonary trunk was divided at the bifurcation level. Continuity between the pulmonary trunk and the aortic arch was established by direct anastomosis or by interposing the xenopericardial roll between them without enlargement of the ascending aorta. The atrial septal defect was enlarged through a right atriotomy. Next, pulmonary blood flow was supplied by an extracardiac xenopericardial conduit ( $6 \mathrm{~mm}$ in diameter and $10 \mathrm{~mm}$ in length) with a bicuspid valve interposed between the right ventricle and the pulmonary artery (Fig 1). After the distal end of the valved conduit was anastomosed to the pulmonary artery the posterior wall of the proximal end of the conduit was anastomosed to the right ventriculotomy $(1 \mathrm{~cm}$ in length) placed at the right ventricular outflow tract. Continuity between the right ventricle and the extracardiac conduit was completely established by means of an oval-shaped xenopericardial patch. All procedures were carried out on the beating heart. Cardiac arrest and total circulatory arrest were not used.

From the Department of Cardiovascular Surgery, Osaka Medical Center and Research Institute for Maternal and Child Health, Osaka, Japan.

Received for publication July 16, 1999; accepted for publication Aug 11, 1999.

Address for reprints: Hidefumi Kishimoto, MD, Department of Cardiovascular Surgery, Osaka Medical Center and Research Institute for Maternal and Child Health, 840 Murodocho, Izumi, Osaka, 594-1101 Japan.

J Thorac Cardiovasc Surg 1999;118:1130-2

Copyright (C) 1999 by Mosby, Inc.

$0022-5223 / 99 \$ 8.00+0 \quad \mathbf{1 2 / 5 4 / 1 0 2 4 7 2}$

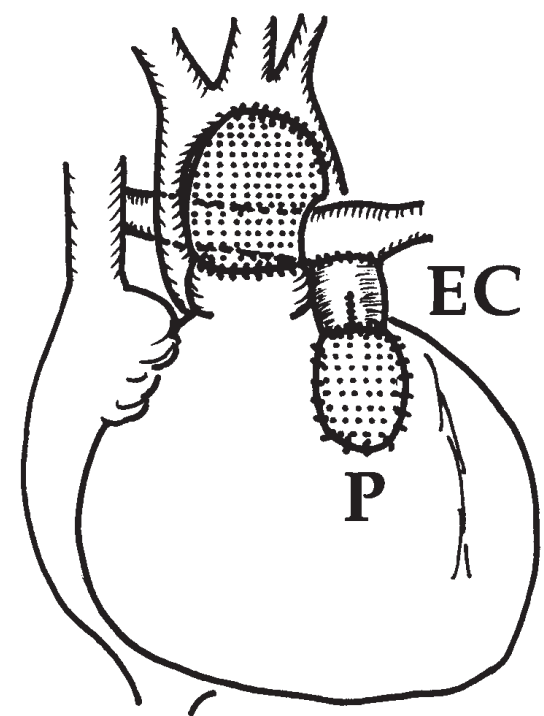

Fig 1. Operative schema showing first-stage Norwood palliation on beating heart. Aortic arch was reconstructed without involving origin of brachiocephalic artery. Pulmonary blood supply was established with extracardiac conduit $(E C)$ from right ventricular outflow tract. Conduit was situated on left side of neoaorta. $P$, Oval-shaped xenopericardial patch.

Illustrative cases. Seven consecutive patients with hypoplastic left heart syndrome, aged 3 to 19 days after birth (mean 13 days) and weighing from 2.4 to $3.3 \mathrm{~kg}(2.8 \mathrm{~kg}$ ), underwent the modified first-stage Norwood operation on the beating heart in our center from June $1992^{5}$ to July 1999 . The diagnosis was aortic stenosis and mitral stenosis in 4 cases, aortic atresia and mitral atresia in 2 cases, and aortic atresia and mitral stenosis in 1 case. Countercurrent aortography showed the diameter of the ascending aorta to range from 1.4 to $6.6 \mathrm{~mm}$ (mean $3.8 \mathrm{~mm}$ ). Blood flow during cardiopulmonary bypass was maintained between 79 and $152 \mathrm{~mL}$. $\mathrm{kg}^{-1} \cdot \min ^{-1}$ (mean $\left.120 \mathrm{~mL} \cdot \mathrm{kg}^{-1} \cdot \mathrm{min}^{-1}\right)$. The lowest rectal temperature was $28.1^{\circ} \mathrm{C}$ to $31.7^{\circ} \mathrm{C}$ (mean $30.0^{\circ} \mathrm{C}$ ).

All patients were easily weaned from bypass without any ischemic events in the coronary circulation. Systemic systolic blood pressure was 54 to $73 \mathrm{~mm} \mathrm{Hg}$ (mean $67 \mathrm{~mm} \mathrm{Hg}$ ) and diastolic pressure was 37 to $54 \mathrm{~mm} \mathrm{Hg}$ (mean $44 \mathrm{~mm} \mathrm{Hg}$ ). All patients underwent delayed sternal closure 3 to 8 days after the operation. There were no operative deaths.

Postoperative cardiac catheterization and cineangiography (Fig 2) demonstrated that the mean pressure of the pulmonary artery was 8 to $18 \mathrm{~mm} \mathrm{Hg}$ with a mean of $13 \mathrm{~mm} \mathrm{Hg}$. Ratio 
Volume 118, Number 6
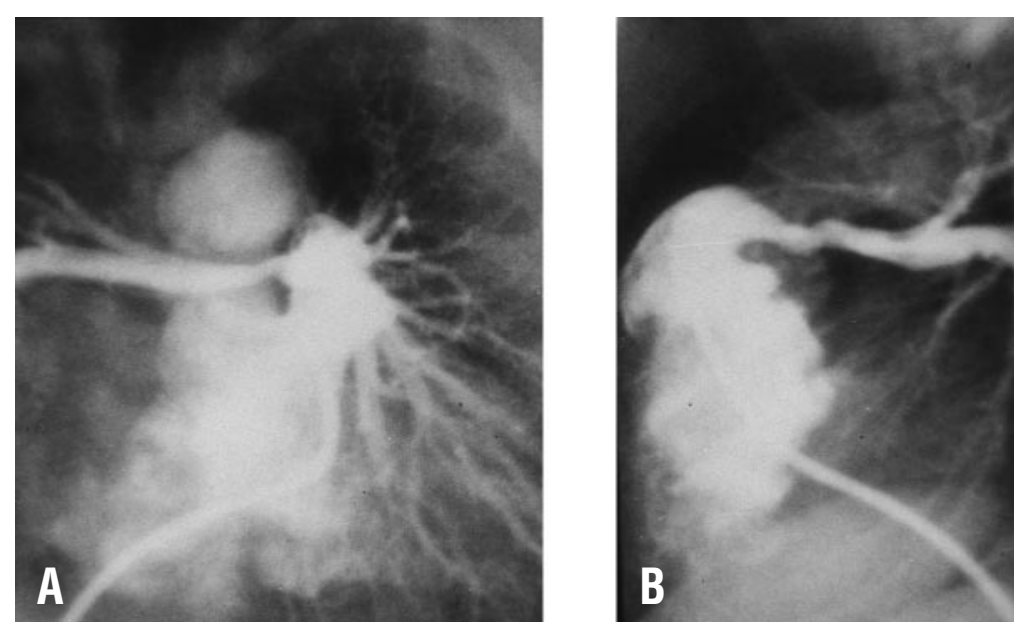

Fig 2. Frontal (A) and lateral (B) views of postoperative ventriculogram showing extracardiac conduit from right ventricular outflow tract to pulmonary artery, lying on left side of neoaorta.

of pulmonary to systemic flow ranged from 0.6 to 1.6 (mean 1.1). Ejection fraction and end-diastolic volume index of the right ventricle ranged from 0.34 to 0.56 (mean 0.42) and 60 to $98 \mathrm{~mL} / \mathrm{m}^{2}$ (mean $82 \mathrm{~mL} / \mathrm{m}^{2}$ ), respectively.

One patient died of hypoxia caused by stenosis of the extracardiac conduit 2 months after the operation ${ }^{5,6}$ and 2 other patients died of heart failure 4 and 29 months after the operation. Another patient underwent a successful Glenn procedure 5 months after the operation, and the 3 remaining patients are currently waiting for the Glenn operation. No patients had postoperative ischemia of the coronary perfusion. Postoperative cardiac catheterization revealed that the ascending aorta grew in accordance with each patient's somatic growth.

Comment. The Norwood operation was reported as a firststage palliation for hypoplastic left heart syndrome in $1980 .^{7}$ In that report the ascending aorta was anastomosed to the pulmonary trunk in a side-to-side fashion under total circulatory arrest. Many surgeons have since carried out the procedure with total circulatory arrest. It is unclear, however, whether enlargement of the ascending aorta under cardiac arrest or total circulatory arrest is needed.

In our series we carried out aortic arch reconstruction without involving the origin of the brachiocephalic artery and used neither total circulatory arrest nor cardiac arrest. In this procedure postoperative myocardial ischemia and ischemia-related events were essential concerns; however, no myocardial ischemia and no ischemia-related events occurred, and there were no operative deaths. In addition to these facts, the ascending aortas grew in accordance with the patients' somatic growth after the operation. Enlargement of the ascending aorta for hypoplastic left heart syndrome may not always be needed. Performing the arch reconstruction without the enlargement of the ascending aorta on a beating heart may be advantageous with respect to cardiac function after the modified Norwood palliation, although the results in the longer-term follow-up need to be investigated in a larger series.

Another concern that nonetheless was not associated with any operative deaths is use of the extracardiac conduit to supply the pulmonary blood flow. Diastolic pressure of the systemic circulation after the Norwood palliation with an extracardiac conduit markedly increased compared with use of a Blalock-Taussig shunt. The increase seemed to be advantageous in systemic perfusion, including the coronary circulation. ${ }^{8}$ However, the ventriculotomy required in this procedure is a possible disadvantage for patients who undergo the Fontan operation in the future. Although postoperative cardiac catheterization and echocardiography showed no significant impairment in ventricular function in our small series, further investigation is necessary to clarify cardiac function after ventriculotomy.

In summary, the first-stage Norwood palliation performed on the beating heart with aortic arch reconstruction and pulmonary blood supply by an extracardiac conduit from the right ventricle but without enlargement of the ascending aorta may be preferable and may provide better survival.

\section{REFERENCES}

1. Noonan JA, Nadas AS. The hypoplastic left heart syndrome: an analysis of 101 cases. Pediatr Clin North Am 1958;5:1029-56.

2. Norwood WI, Lang P, Hansen DD. Physiologic repair of aortic atresia-hypoplastic left heart syndrome. N Engl J Med 1983;308:23-6.

3. Jonas RA, Lang P, Hansen D, Hickey P, Castaneda AR. Firststage palliation of hypoplastic left heart syndrome: the importance of coarctation and shunt size. J Thorac Cardiovasc Surg 1986;92:6-13

4. Kern JH, Hayes CJ, Michler RE, Gersony WM, Quaegebeur JM. Survival and risk factor analysis for the Norwood procedure for hypoplastic left heart syndrome. Am J Cardiol 1997;80:170-4.

5. Kishimoto H, Iio M, Kume Y, et al. The Norwood operation for 
hypoplastic left heart syndrome using a valved pericardial roll between the right ventricle and pulmonary artery [abstract]. Cardiol Young 1993;3:162.

6. Kawahira Y, Kishimoto H, Kawata H, et al. Surgical atrial septostomy without cardiopulmonary bypass. Ann Thorac Surg 1996;61:1016-8.
7. Norwood WI, Kirklin JK, Sanders SP. Hypoplastic left heart syndrome: experience with palliative surgery. Am J Cardiol 1980;45: 87-91.

8. Duncker DJ, Ishibashi Y, Bache RJ. Effect of treadmill exercise on transmural distribution of blood flow in hypertrophied left ventricle. Am J Physiol 1998;275(4 Pt 2):H1274-82. 